\title{
Myelopathy: An Unusual Presentation of Toxoplasmosis
}

\author{
S. Nag and A.C. Jackson
}

\begin{abstract}
Central nervous system toxoplasmosis is a well known disease of immunocompromised patients. Neuropathologic examinations have only rarely demonstrated spinal cord involvement. This report describes a fatal case of toxoplasmosis that presented with a subacute myelopathy. Toxoplasmosis should be considered in immunocompromised patients, including patients with the acquired immune deficiency syndrome, that develop intramedullary lesions of the spinal cord.
\end{abstract}

RÉSUMÉ: La myélopathie: un mode de présentation inusité de la toxoplasmose La toxoplasmose du système nerveux central est une maladie bien connue chez les patients immunocompromis. L'atteinte de la moëlle épinière a rarement été démontrée à l'examen neuropathologique chez ces patients. Nous rapportons un cas de toxoplasmose fatale dont le mode de présentation a été une myélopathie subaiguë. La toxoplasmose doit être envisagée chez les patients immunocompromis, incluant les patients atteints du syndrome d'immunodéficience acquise, qui développent des lésions intramédullaires de la moëlle épinière.

Can. J. Neurol. Sci. 1989; 16: 422-425

There are many reports in the literature of central nervous system (CNS) toxoplasmosis in patients with impaired immunologic defense mechanisms due to immunosuppressive therapy or the acquired immune deficiency syndrome (AIDS)..$^{1-8}$ The spinal cord is not usually involved in this disease. Cases of CNS toxoplasmosis presenting with a myelopathy have rarely been recognized.9-11 This case report describes a patient treated with cyclophosphamide for an idiopathic autoimmune hemolytic anemia who presented with a myelopathy, and was found to have a toxoplasmic myelitis at autopsy.

\section{Case Report}

A 58-year-old female presented with left-sided weakness and sensory loss. An idiopathic autoimmune hemolytic anemia was diagnosed five years earlier. She was initially treated with prednisone, and one year later she was switched to cyclophosphamide $150 \mathrm{mg} /$ day.

Two months prior to admission she developed burning discomfort inferior to her left breast that involved her left lower trunk and left leg. The discomfort persisted and became associated with mild left leg weakness which progressed until she was unable to walk. She also had a 30 pound weight loss over six months prior to admission. She had a domestic cat.

On examination she had mild proximal weakness of the right leg and severe left leg weakness that was more marked proximally. There was sensory loss to pinprick below T5 level with greater involvement on the right side, and a loss of light touch below T6 level on the left.
Position sense was impaired in the left leg. Abdominal reflexes were absent and deep tendon reflexes were brisk in the legs. The left toe was upgoing.

On admission a pancytopenia was present with a leukocyte count of $1.8 \times 10^{9} / \mathrm{L}$ and a platelet count of $66 \times 10^{9} / \mathrm{L}$. The hemoglobin level was $101 \mathrm{~g} / \mathrm{L}$. A bone marrow aspiration showed moderate marrow hypoplasia and dyserythropoiesis. A CT myelogram revealed mild enlargement of the spinal cord at T5. A CSF examination revealed $8 \times 10^{6} / \mathrm{L}$ mononuclear cells, and the protein and glucose levels were $0.76 \mathrm{~g} / \mathrm{L}$ and $3.1 \mathrm{mmol} / \mathrm{L}$, respectively. No atypical cells were present and cultures were negative.

She was treated with corticosteroids (initially prednisone $100 \mathrm{mg} /$ day), which did not result in significant improvement in her weakness or sensory loss. On her 11 th hospital day she became irritable and developed flaccid paraplegia with urinary and fecal incontinence. She had fever $\left(39^{\circ} \mathrm{C}\right.$, rectal) on the following day that persisted despite intravenous antibiotics. She also developed persistent hematuria, and cyclophosphamide was discontinued.

She became comatose on her 16th hospital day and developed left arm weakness and nuchal rigidity. A CT head scan revealed low density lesions bilaterally in the frontal lobes with minimal enhancement, and a low density lesion in the right basal ganglia (Figure 1). A repeat CSF examination revealed $20 \times 10^{6} / \mathrm{L}$ white cells $(58 \%$ polys, $42 \%$ mononuclear cells), protein was $1.16 \mathrm{~g} / \mathrm{l}$, glucose was $2.1 \mathrm{mmol} / \mathrm{L}$, and cultures were negative. The platelet count dropped to $33 \times 10^{9} / \mathrm{L}$. A brain biopsy was not performed because of the high risk of a hemorrhagic complication. She was given broad antimicrobial coverage with intravenous penicillin, ceftazidime, metronidazole, and amphotericin B for a suspected CNS infection. She died on her 22 nd hospital day.

From the Departments of Pathology (Neuropathology) (S.N.) and Medicine (Neurology) (A.C.J.), Queen's University and Kingston General Hospital, Kingston

Received March 9, 1989. Accepted June 6, 1989

Reprint requests to: Dr. S. Nag, Department of Pathology, Queen's University, Kingston, Ontario, Canada K7L 3N6 


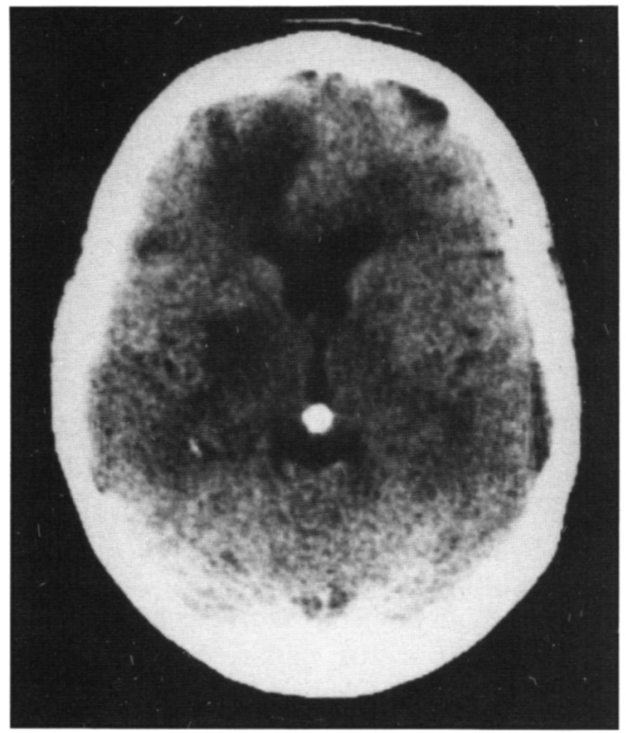

Figure I - Non-contrast C.T. scan of head showing hypodensities in both frontal lobes and in the basal ganglia region on the right side.

\section{AUTOPSY Findings}

The spinal cord showed swelling and greyish discoloration extending from T5-T8 levels. Microscopic examination of the cord at these levels revealed coagulative necrosis involving the cross-sectional area with some sparing of the peripheral rim on the right side. At the periphery of the necrotic zone, ghost outlines of necrotic macrophages were evident. The vessels in this region showed endothelial swelling and thickening of their walls with eosinophilic material which likely represented protein exudation. However, because the reaction was a few weeks old, the material no longer gave a positive reaction for fibrin using the phosphotungstic acid hematoxylin stain. Axonal swellings and some remaining myelinated fibers were present at the periphery of the cord on the right side.

The area rostral and caudal to the T5-T8 levels showed evidence of ongoing active inflammation with necrosis of the neuropil associated with an inflammatory reaction consisting mainly of polymorphonuclear leukocytes (Figure 2A). The microvessels in this area showed fibrin in their lumen, and walls, with extravasation into the surrounding neuropil. Free tachyzoites of Toxoplasma were identified in these areas by light and electron microscopy (Figures 2B).

More rostral sections taken at C8 level revealed Wallerian degeneration of the posterior columns. Multiple microglial nodules were observed in the grey matter at this level. In addition, cysts of Toxoplasma gondii were identified (Figure 2C).

The brain was diffusely swollen and showed flattening of gyri. Both frontal lobes showed yellow-brown depressed areas measuring about $2 \mathrm{cms}$ in diameter in a parasaggital location. On microscopy, the cellular and vascular changes were few weeks old and resembled the changes observed in the T5-T8 spinal cord levels. In addition, thrombosed arterioles with recanalisation of the lumina were present, suggesting that the tissue necrosis was secondary to vascular occlusion. Perivascular collections of lymphocytes were present in the brain and the subarachnoid space.
Horizontal sections of the brain showed additional areas of necrosis in the occipital lobes, both basal ganglia, cerebellum, right side of the midbrain, and the right side of the basis pontis (Figure 3). On microscopy, these areas showed active ongoing inflammation, similar to that seen in the spinal cord.

Examination of other body organs did not reveal evidence of toxoplasmosis. The heart showed a few areas of interstitial inflammation which were consistent with toxoplasma myocarditis, however, no organisms were identified on special stains. Examination of the hematopoietic system showed pancytopenia and mild hypoplasia and dyserythropoiesis of the bone marrow and lymphoid atrophy of the spleen and lymph nodes. These findings are related to the immunosuppressive effect of chemotherapy. The liver and spleen showed mild hemosiderosis consistent with autoimmune hemolytic anemia.

Postmortem serum had an antibody titre of 1/4096 to Toxoplasma (immunofluorescent antibody test). Human immuno-deficiency virus serology was negative.

\section{Discussion}

This patient with fatal CNS toxoplasmosis was immunosuppressed from treatment of an autoimmune hemolytic anemia with cyclophosphamide. She developed a left-sided intramedullary thoracic cord lesion that subsequently became bilateral. After initiation of corticosteroids, there was extension of the spinal cord lesion and the development of symptomatic multifocal brain lesions. It was clinically uncertain whether the spinal cord and brain lesions were part of the same pathologic process. The development of thrombocytopenia prevented a specific diagnosis of the cerebral lesions with a brain biopsy, and the patient died despite treatment with multiple antimicrobial agents for a suspected CNS infection. Neuropathologic examination showed that the spinal cord and brain lesions were due to Toxoplasma infection.

Patients with impaired immunologic defense mechanisms are at risk of developing CNS toxoplasmosis. These patients often have underlying systemic diseases and are treated with immunosuppressive therapy. Autoimmune hemolytic anemia has been reported as an underlying condition in toxoplasmosis in one other case. ${ }^{2}$ Toxoplasmosis has been frequently observed in patients with AIDS. 3,4,5,7,12,13 In fact, toxoplasmosis has been recognized as the most common cause of focal brain lesions in patients with AIDS. 12

Pathologic evidence of spinal cord involvement in CNS toxoplasmosis has been recognized infrequently. At autopsy, spinal cord involvement was observed in only one of 16 patients with CNS toxoplasmosis and AIDS. ${ }^{5}$ Townsend et al ${ }^{8}$ found spinal cord involvement in one of 6 cases of CNS toxoplasmosis without AIDS. It is unclear whether spinal cord lesions were recognized clinically in these two cases.

There have been three previous reports of patients presenting with a myelopathy associated with Toxoplasma infection. Mehren et al ${ }^{10}$ reported an AIDS patient who presented with a cervical myelopathy. This patient also had localized enlargement of the spinal cord on myelography and a CSF pleocytosis. At autopsy, Toxoplasma tachyzoites and cysts were found in the cervical spinal cord and brain. This is the only other well documented case of Toxoplasma myelitis. Mishra et al ${ }^{11}$ described a patient with a myelopathy and myelographic blocks at T7 and 


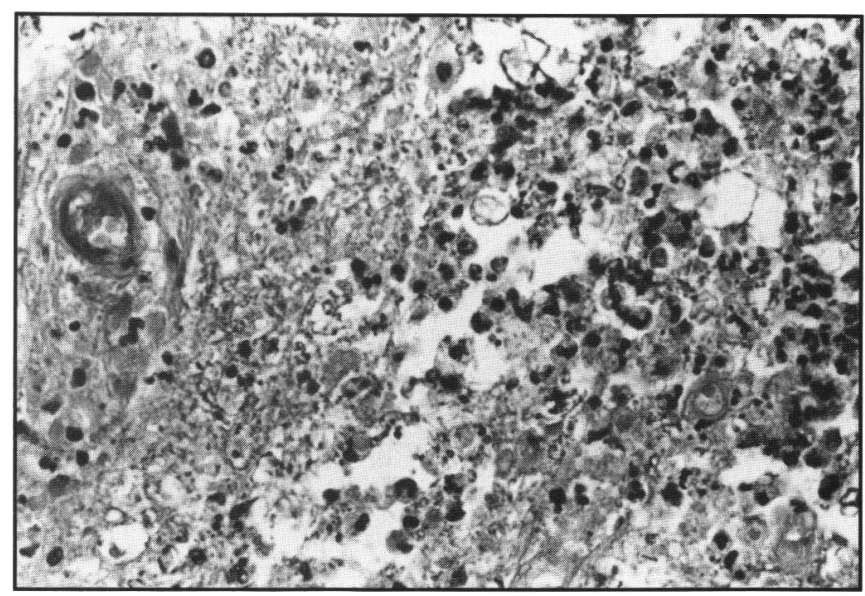

A

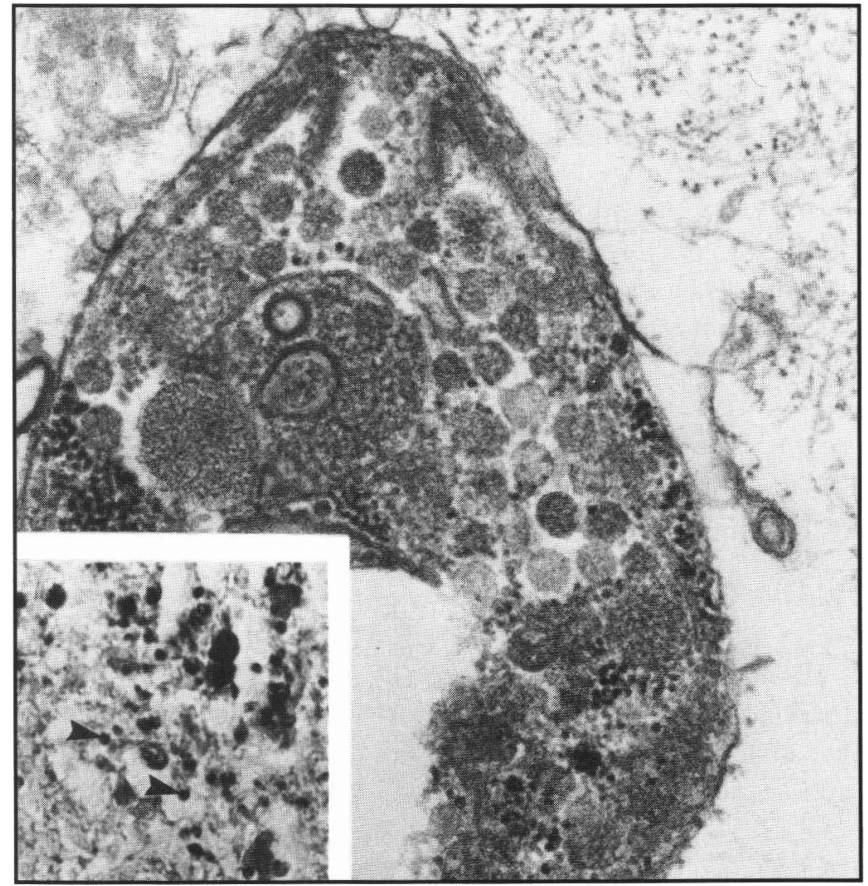

B

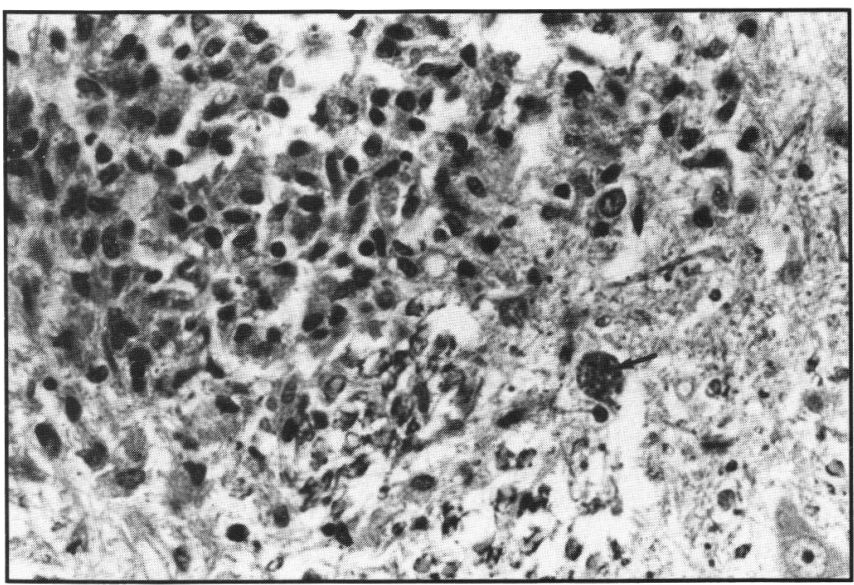

C
Figure $2-(A)$ An area of active inflammation showing necrosis of the neuropil and a severe polymorphonuclear response. Fibrin is present in the lumen and wall of a microvessel. Tachyzoites of Toxoplasma were easily identified in areas of necrosis $(B)$. The grey matter of the cord at C8 level showing a microglial nodule at the periphery of which a Toxoplasma cyst (arrow) is present. (A) $x 300$, (B) $\times$ 57,000; inset $\times 400$, Geimsa stain; (C) $\times 400$

L2. A biopsy of granulation tissue in the epidural and subarachnoid space showed toxoplasmosis. Koh et al ${ }^{9}$ reported a patient with an acute transverse myelopathy, mild CSF pleocytosis, and serologic evidence of Toxoplasma infection. However, there was no pathologic confirmation that this was a toxoplasmic myelitis.

Although toxoplasmic myelitis is uncommon, it should be suspected in immunocompromised patients presenting with intramedullary lesions of the spinal cord. Determinations of serum and CSF titers of Toxoplasma antibodies may be helpful in making an antemortem diagnosis of CNS toxoplasmosis. ${ }^{4,14}$ Cerebral toxoplasmosis can respond to therapy with the combination of sulfadiazine and pyrimethamine, $4,13,15$ and it would be expected that this therapy might also be beneficial in cases of toxoplasmic myelitis.

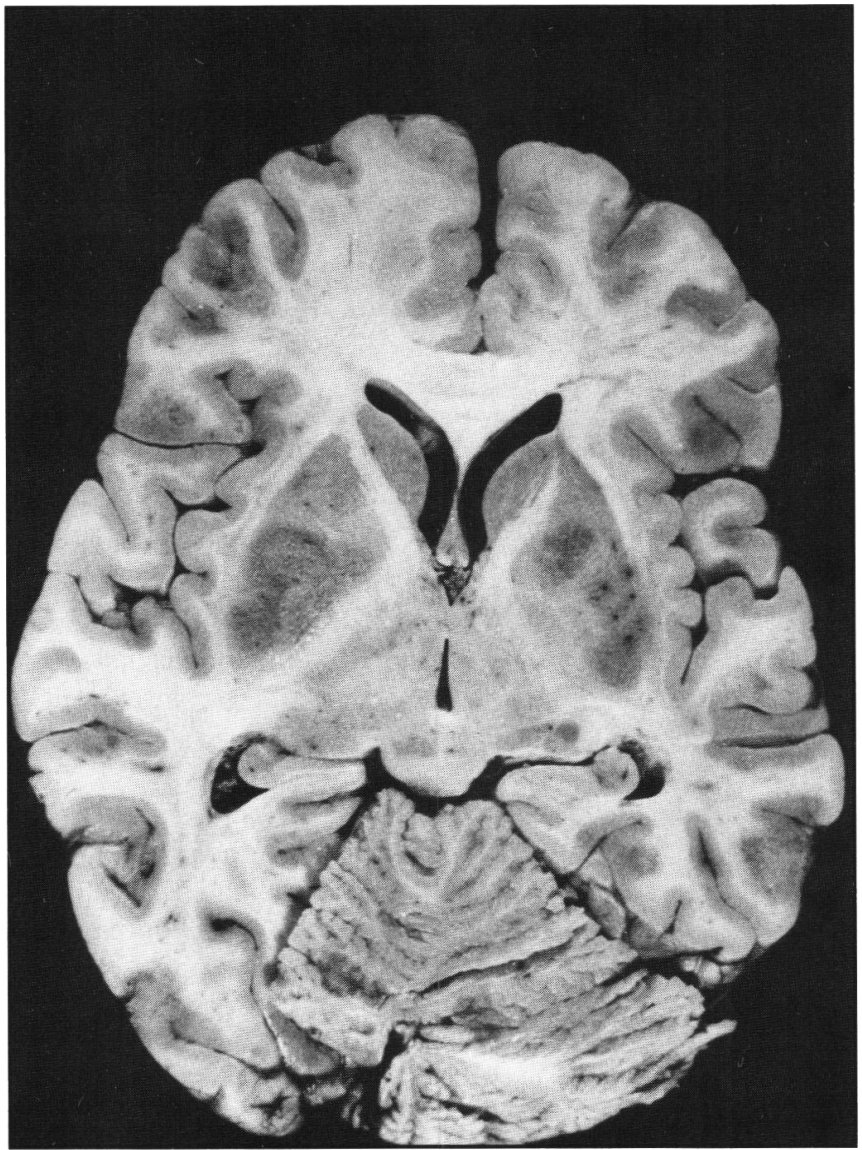

Figure 3 - Horizontal section of brain showing areas of necrosis in both frontal lobes and basal ganglia and in multifocal areas of the cortex and cerebellum. The centrum semiovale is enlarged due to cerebral edema associated with the frontal lobe lesions. 


\section{ACKNOWLEDGEMENTS}

The technical assistance provided by Mrs. B. LeClaire and Mrs. V. Norkum are gratefully acknowledged.

\section{REFERENCES}

1. Frenkel JK, Nelson BM, Arias-Stella J. Immunosuppression and toxoplasmic encephalitis: clinical and experimental aspects. Hum Pathol 1975; 6: 97-111.

2. Gleason TH, Hamlin WB. Disseminated toxoplasmosis in the compromised host: a report of five cases. Arch Intern Med 1974: 134: 1059-1062.

3. Levy RM, Bredesen DE, Rosenblum ML. Neurological manifestations of the acquired immunodeficiency syndrome (AIDS): experience at UCSF and review of the literature. J Neurosurg 1985; 62: 475-495

4. Luft BJ, Remington JS. Toxoplasmosis of the central nervous system. In: Remington JS, Swartz MN, eds. Current Clinical Topics in Infectious Diseases, Volume 6. New York: McGraw-Hill Book Company, 1985; 315-358.

5. Navia BA, Petito CK, Gold JWM, et al. Cerebral toxoplasmosis complicating the acquired immune deficiency syndrome: clinical and neuropathological findings in 27 patients. Ann Neurol 1986; 19: 224-238.

6. Ruskin J, Remington JS. Toxoplasmosis in the compromised host. Ann Intern Med 1976; 84: 193-199.
7. Snider WD, Simpson DM, Nielsen S, et al. Neurological complications of acquired immune deficiency syndrome: analysis of 50 patients. Ann Neurol 1983; 14: 403-418.

8. Townsend JJ, Wolinsky JS, Baringer JR, et al. Acquired toxoplasmosis: a neglected cause of treatable nervous system disease. Arch Neurol 1975; 32: 335-343.

9. Koh C-S, Tsukada N, Yanagisawa N, et al. A case of acute acquired toxoplasmosis with acute transverse myelopathy. Clin Neurol 1981; 21: 158-164.

10. Mehren M, Burns PJ, Mamani F, et al. Toxoplasmic myelitis mimicking intramedullary spinal cord tumor. Neurology 1988; 38: 1648-1650.

11. Mishra DN, Gupta RC, Atal PR, et al. Toxoplasmosis in an adult presenting as paraparesis (a case report). J Assoc Physicians India 1975; 23: 779-781.

12. Holliman RE. Toxoplasmosis and the acquired immune deficiency syndrome. J Infect 1988; 16: 121-128.

13. Luft BJ, Remington JS. Toxoplasmic encephalitis. J Infect Dis 1988; 157: 1-6.

14. Suzuki Y, Israelski DM, Dannemann BR, et al. Diagnosis of toxoplasmic encephalitis in patients with acquired immunodeficiency syndrome by using a new serologic method. J Clin Microbiol 1988; 26: 2541-2543.

15. Wanke C, Tuazon CU, Kovacs A, et al. Toxoplasma encephalitis in patients with acquired immune deficiency syndrome: diagnosis and response to therapy. Am J Trop Med Hyg 1987; 36: 509 516. 